\title{
External reference samples for residual stress analysis by X-ray diffraction
}

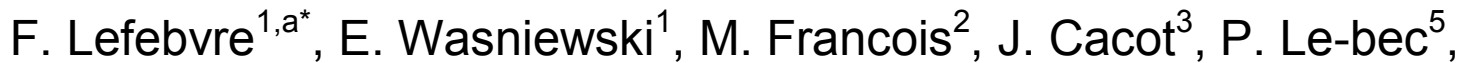

E. Baumhauer ${ }^{4}$, D. Bouscaud ${ }^{6}$, T. Bergey ${ }^{7}$, D. Blaize ${ }^{7}$, D. Gloaguen ${ }^{8}$, A. Cosson ${ }^{9}$, S. Jegou ${ }^{6}$, Y. Cheynet ${ }^{10}$, S. Leray ${ }^{12}$, M. Meheux ${ }^{11}$, JC. Monvoisin ${ }^{7}$, P. Allain ${ }^{13}$, JC. Vidal $^{14}$, JM. Sprauel $^{15}$, P. Goudeau $^{16}$, C. Charles ${ }^{1}$, L. Daflon ${ }^{1}$, C. Fischer ${ }^{6}$, L. Desmas ${ }^{17}$, A. Ouakka ${ }^{18}$, MJ. Moya $^{8}$, Y. Bordiec ${ }^{19}, \mathrm{H}$. Hamdi $^{20}$

${ }^{1}$ CETIM, 52 avenue Félix Louat, Senlis, 60304, France,

${ }^{2}$ LASMIS, UTT, 12 rue Marie Curie, BP2060, 10010 Troyes cedex, France

3 AIRBUS OPERATIONS SAS, ESMUT / Materials \& Processes - Metal technology, Toulouse,

${ }^{4}$ PSA Centre technique de Belchamp - DTI/DITV/PMXP/TAC/AEM, 25218 Montbéliard

${ }^{5}$ EDF, R\&D-Dépt MMC, avenue des Renardières, 77818 Moret-sur-Loing cedex

${ }^{6}$ Arts et Métiers ParisTech (Angers, Aix en Provence, Metz, Paris)

${ }^{7}$ SAFRAN (Bordes, Corbeil, Vernon)

${ }^{8}$ EMM - GeM, I.U.T. de Saint-Nazaire, 58 rue Michel Ange B.P. 42044606 Saint Nazaire

${ }^{9}$ SKF, Laboratoire GTD 204, boulevard Charles de Gaulle 37540 Saint Cyr sur Loire

${ }^{10}$ SNCF, AEF-MES2, 21 avenue du président Allende, 94407 Vitry sur Seine

${ }^{11}$ ASCOMETAL, CREAS, BP 70045, 57301 Hagondange

${ }^{12}$ Metal Improvement Company, 1065 avenue du Maréchal Juin, ZI, 45200 Amilly

${ }^{13}$ DCNS BU Propulsion-Indret CESMAN 44620 La Montagne

${ }^{14}$ RENAULT (Dimat), 1, avenue du golf, Service 68130 - API : TCR LAB 035, 78288 Guyancourt

${ }^{15}$ Université de la Méditerranée, IUT, Avenue Gaston Berger, 13625 Aix en Provence

${ }^{16}$ Institut Pprime, SP2MI, Bd Marie et Pierre Curie, BP30179 86962 Futuroscope

${ }^{17}$ MELIAD, 6 rue des Orfèvres, 44840 Les Sorinières

${ }^{18}$ SOGEFI Group - Suspension Components Division, 201Rue Sin-Le-Noble, 59500 Douai

${ }^{19}$ SONATS, 2 rue de la Fonderie, BP40538, 44475 Carquefou

${ }^{20}$ LTDS, ENISE, 58, rue Jean Parot, 42023 Saint-Étienne

afabien.lefebvre@cetim.fr

Keywords: Residual stress, External reference samples, Round robin

\begin{abstract}
.
The GFAC (French Association for residual stress analysis) has been working for several years on external reference samples in relation with the EN 15305-2009 standard. The purpose of this campaign is to provide an external reference sample to each laboratory involved in the round-robin to allow a good calibration, a good quality control of their X-ray diffraction system and an easiest way to compare results between laboratories. All the procedures to qualify external reference materials will be described in the paper.
\end{abstract}

\section{Introduction}

The French association for residual stress analysis (GFAC) is an association affiliated to the French Society for Metallurgy and Materials (SF2M) and French Association of Mechanics (AFM). Many of the French academics and industrial laboratories using different methods for residual stress analysis such as X-ray diffraction, hole drilling, magnetic or ultrasonic methods..., belong to this association..

For several years, studies have been carried out on standardization activities, which lead to the first French Standard for residual stress analysis by X-ray diffraction [1], in comparison with laboratories practices, with a first round-robin campaign between 1992 and 1995 [2]. 
Following the French standard XPA 09-285 [3, 4, 5], the EN 15305 standard [6] was introduced in 2009 with some recommendations and requirements about the use of external reference samples. Consequently, a new workgroup of the GFAC association with 28 participants of industries and universities, co-authors of this paper, was created to work on external reference samples in relation with EN 15305-2009 standard. Eight materials were chosen: ferritic steel, martensitic steel, aluminium alloy, titanium alloy, two types of nickel-chromium alloy, and tungsten thin films deposited on silicon substrates. The purpose of this paper is to present the procedure and results for one of them: the NiCr30Fe (Inconel 690) alloy.

\section{Experimental procedures}

The geometry of the samples was 20x30x $10 \mathrm{~mm}^{3}$. They were shot-peened by Metal Improvement Company to obtain homogenous stresses on the surface.

Seven different diffractometers were used in this study: PRECIX, SEIFERT XRD 3003 PTS, PROTO, SET-X, BRUKER AXS D8, STRESSTECH and SIEMENS D5000.

For the $\mathrm{NiCr}_{30} \mathrm{Fe}$ (Inconel 690) alloy, the shot peening parameters were defined as follow: BC210/F18-F26N/125\%. Residual stresses determination was carried out using Mn-K $\alpha$ radiation with the $\{311\}$ crystallographic planes.

For all materials, a minimum of $13 \psi$ tilt angles was chosen with a spot size smaller than $4 \mathrm{~mm}$ at $\psi$ $=0$. No mask or oscillation was used. The values of X-ray Elasticity Constants, $1 / 2 S_{2}$ and $S_{1}$, were those defined in the EN15305 standard. The scanning/counting time was not specified but the standard deviations had to be between \pm 15 and $\pm 25 \mathrm{MPa}$ as calculated with least squares residue and statistical counting error, respectively. No indication in terms of residual stress calculation method was given; the choice of the method to determine peak shifts was done by the laboratory according to their X-ray diffraction system, software and experience.

Samples are identified by one letter for each material, for example $\mathrm{F}$ for ferritic samples or I for Inconel 690 samples, and laboratories by a letter. At the beginning of the campaign, the homogeneity was checked for each material by five measurements on a sample and then each sample was analysed by the leader of the material group before round robin. Following recommendations of ISO 5725 standard [7], an analysis network has been then defined between all laboratories: each sample has to be analysed three times by a laboratory and by at least three laboratories. It means that a given specimen is analysed at least nine times with a minimum of 10 samples and maximum of 40 samples by material. Each laboratory received seven samples grouped into sets of three. So a minimum of $21 \mathrm{X}$-ray diffraction measurements need to be performed.

As said previously, residual stress calculation method has been left free for each partner. However all the X-ray patterns were saved and sent to be treated by a program called StressDiff. StressDiff software is dedicated to the acquisition and processing of the X-ray data for the evaluation of the constraints. This package was developed as a result of Stress AT program. Four calculation methods (centroid, middle point, maximum of peak, fitting...) were used to analyse the results.

Following the ISO5725 standard on accuracy (trueness and precision) of measurement methods and results [7], the aim was to obtain for each reference sample:

- $R_{\sigma}$ : reproducibility of residual stress value (global standard deviation)

- $r_{\sigma}$ : repeatability of the residual stress value (standard deviation of repeated measurements in one laboratory under repeatability conditions)

- $\sigma_{\text {mean }}$ : mean stress value of the results of a given laboratory

- $\sigma_{\text {general }}$ : general mean stress of a given sample

- $\sigma_{\text {material }}$ : material mean stress (on all the samples and all the laboratories)

These parameters were calculated for each reference sample, for each material and for each residual stress calculation method. 


\section{Results and discussion}

Fig.1 illustrates the $345(115 \times 3)$ results for one type of calculation (parabola method) for the Inconel 690 samples. The results show some dispersion. Fig.2 presents the results of reproducibility and repeatability in function of calculation method. Values above $100 \mathrm{MPa}$ up to $350 \mathrm{MPa}$ were obtained. They are not acceptable to produce reference samples.

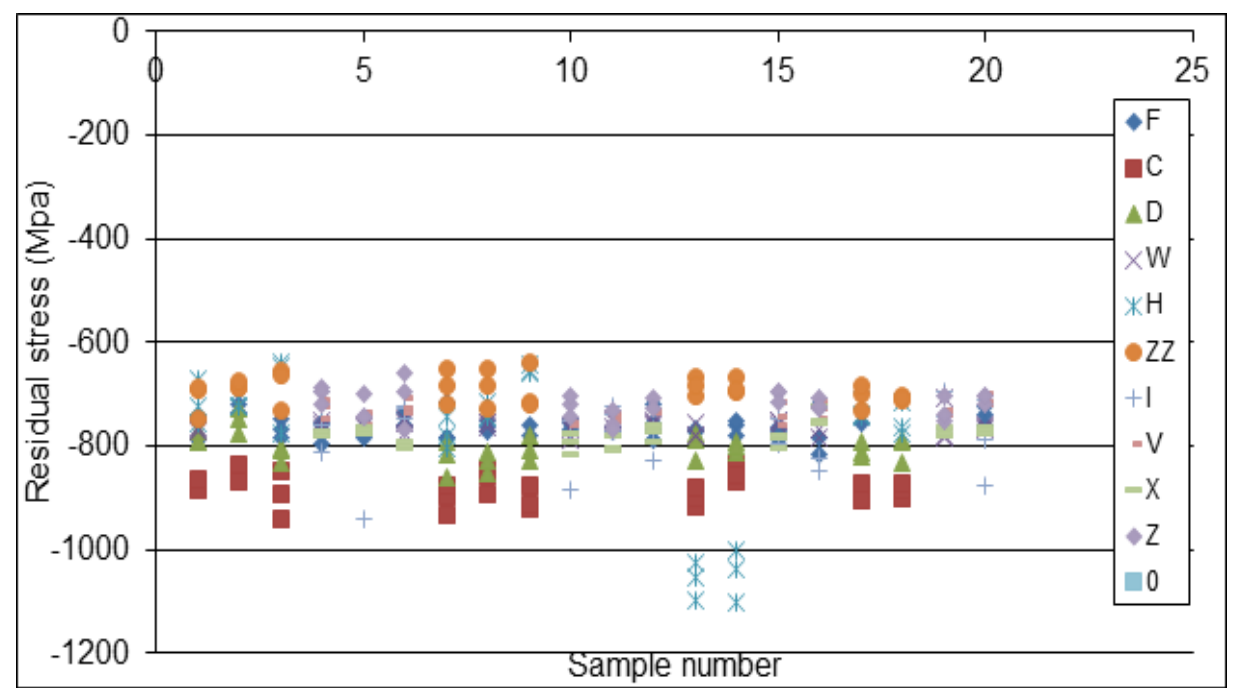

Fig. 1 Residual stress results (in $\mathrm{MPa}$ ) calculated by the parabola method. Each letter corresponds to a different laboratory

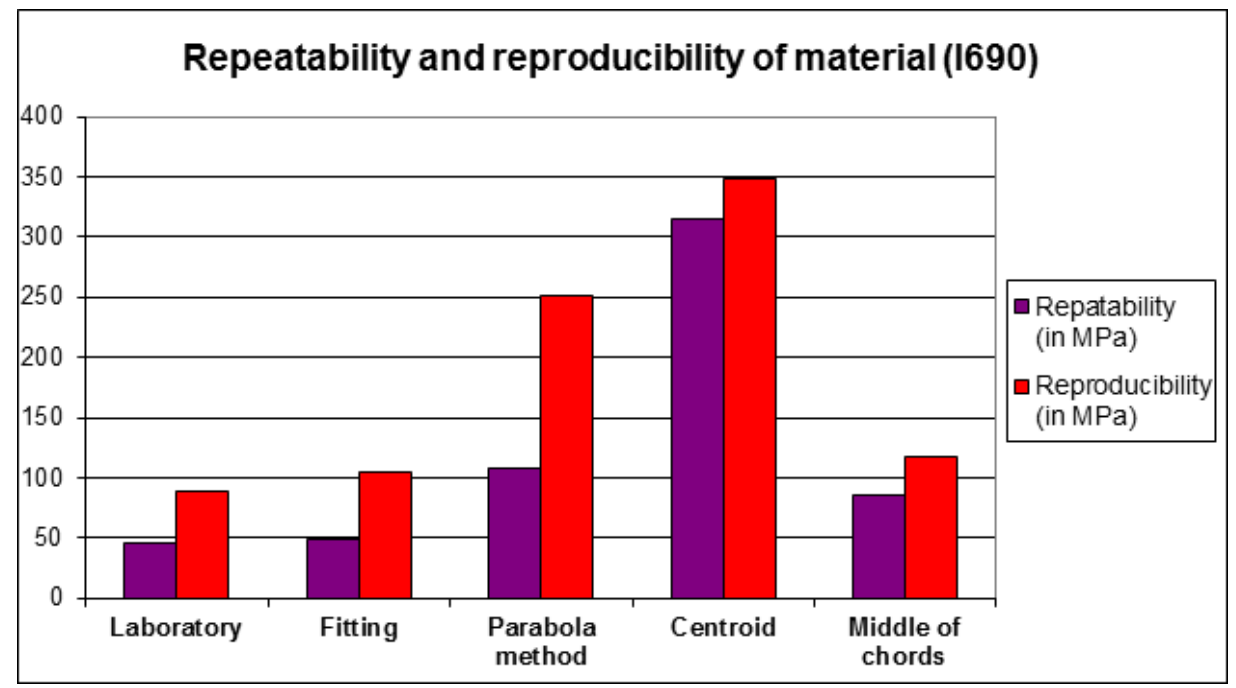

Fig. 2 Repeatability and reproducibility (in MPa) of all population for the nickel-chromium (I690)

Besides removing some unusable files, a series of tests was performed following the ISO 5735-2 standard [7]. It included a systematic application of statistical tests for outliers. It was decided to use a method by calculating a tolerance band.

The calculation of the tolerance band was calculated from the average value and reproducibility, according to $\sigma_{\text {lower band }}=\sigma_{\text {mean }}-R_{\sigma}$ and $\sigma_{\text {upper band }}=\sigma_{\text {mean }}+R_{\sigma}$

So values not included in this tolerance interval were then considered as outliers. These values were suppressed and the calculations of the average values and reproducibility were recalculated. These values have changed, and the tolerance interval has also changed. So a new iteration of calculation was realized. This method was repeated until all remaining values were included in the tolerance interval. 
This method was used to analyze nickel-chromium alloy results presented in Fig. 1. The tolerance interval for two iterations is presented in Fig. 3. When some data were outside the tolerance interval after iteration, they were deleted for the new calculation.

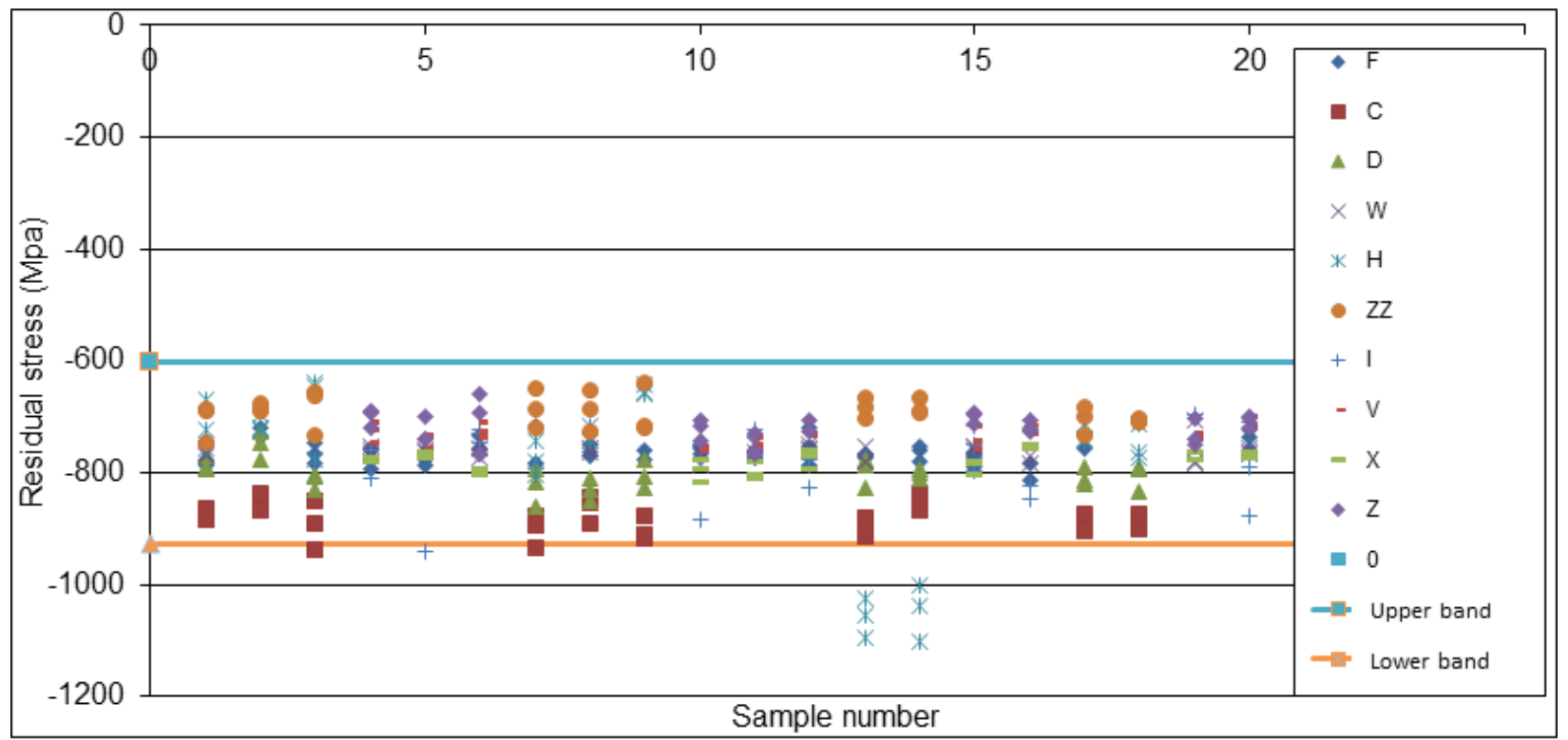

First iteration

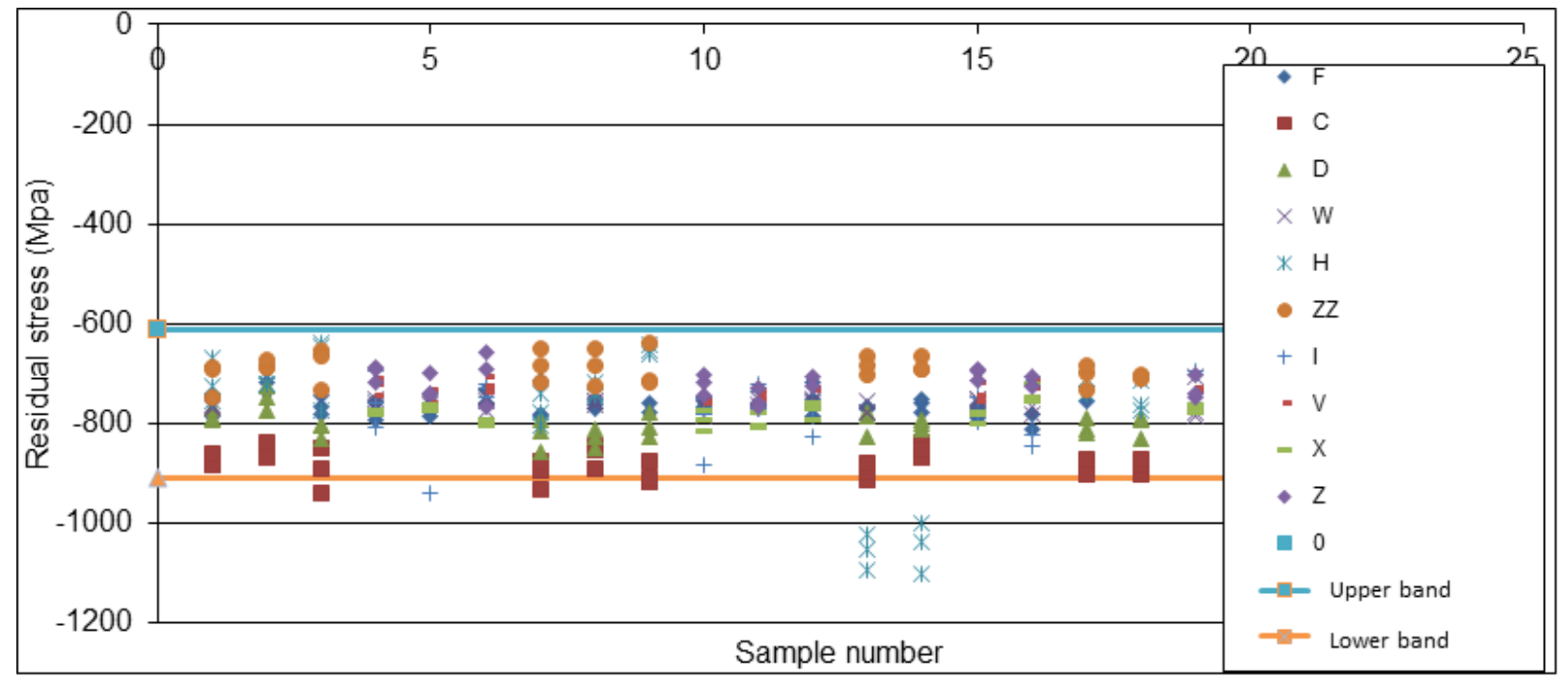

Second and final iteration

Fig. 3 Residual stress results by maximum peak calculation with tolerance interval

The new repeatability and reproducibility were therefore calculated (see Fig. 4). With this statistical method to remove outliers, they decreased for all stress calculation methods. So, it was decided to use this protocol to validate the reference samples for the Nickel-Chromium alloy. 


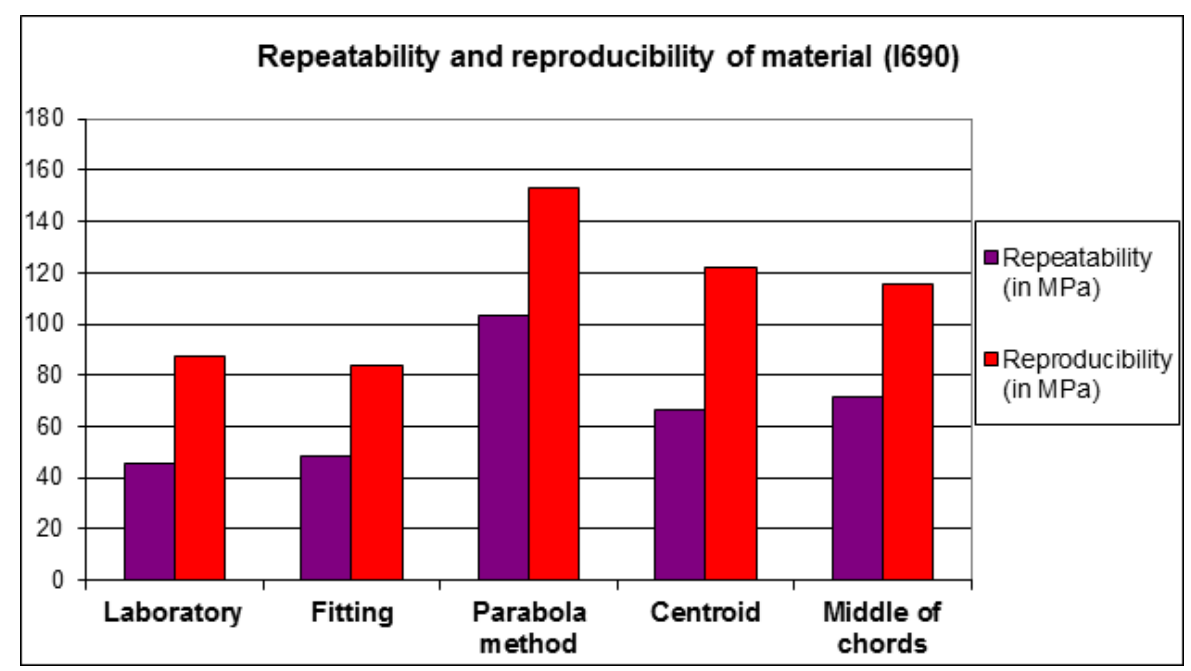

Fig. 4 Repeatability and reproducibility (in MPa) of all population for the nickel-chromium (I690) after new statistical treatment

\section{Conclusion}

The purpose of this external round-robin campaign organized by the GFAC working group was to give opportunities for each laboratory involved in this campaign test to obtain external reference samples for each tested material. Such samples are required by the EN 15305-2009 standard and are used for calibration purpose, quality control of X-ray diffraction equipment and are helpful for the comparison between laboratories. The ultimate goal of this GFAC external references campaign was the creation of a common procedure for qualification of external samples and through the GFAC association the commercialization of certified external reference samples.

For the nickel-chromium alloy (I690), the reference samples are validated and sent to ten laboratories involved in the round-robin of the material. The appendix of this paper presents the certificate of one sample which includes the main information about it (reference, fabrication, mean values and variances for the material, mean values and variances for the given sample, X-ray parameters, or how to use the data in relation to the EN15305 standard).

For the other materials, the analyses are still in progress.

APPENDIX : Certificate

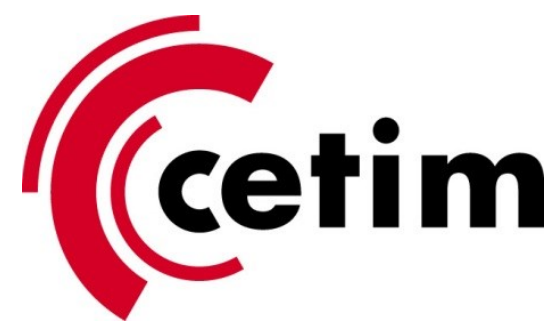

\section{APPENDIX GFAC Certificat}

Reference sample for residual stress analyses by X-ray diffraction

- Sample: GFAC2013I01

- Sample fabrication: Electricité de France (EDF)

- Material: $\mathrm{NiCr}_{30} \mathrm{Fe}$ (Inconel 690)

- Metallurgical state: recristallised at $1040{ }^{\circ} \mathrm{C}+5 \mathrm{~h} 700{ }^{\circ} \mathrm{C}$

- Grain size: 40 à $60 \mu \mathrm{m}$

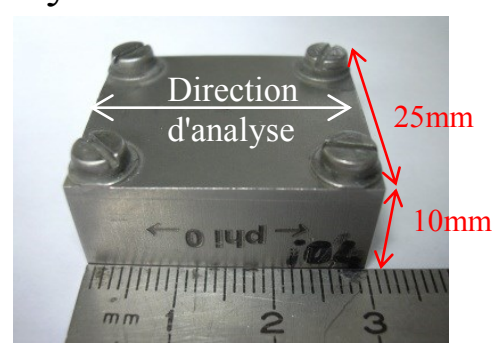

- Mechanical state: shot peened (Metal Improvement Compagny MIC) /

Parameters: BC210/F18-F26N/125\%/spécif. AMS S 13165 (réf. essai: 2642)

- Certificate date: XX/XX/2013

- Information on this certificate is archived by the CETIM. The sample and its certificate should not be separated. 
- This certificate contains 2 pages. It may not be reproduced or disclosed without a complete change of text. Certificates without signature and stamp are not valid.

- Area of application covered by the certificate: this sample can be used for quantification and verification of a goniometer as defined in EN 15305, paragraph 11.3. It is a reference sample with stress within the meaning of EN 15305, Chapter 11.

- For its realization and its characterization, precautions were taken to secure the stability of the residual stresses (storage at room temperature in a dry air). However, this stability is not guaranteed by this certificate.

- The calculation of sample characteristics was carried out according to the requirements of ISO 5725. Certification requirements are described in the document: 063333_GFAC2013_FL_EW

- Material characteristics:

\begin{tabular}{|c|c|c|c|c|c|}
\hline$\sigma_{\mathrm{m}}$ & $\mathrm{r}_{\sigma \mathrm{m}}$ & $\mathrm{R}_{\sigma \mathrm{m}}$ & $\tau_{\mathrm{m}}$ & $\mathrm{r}_{\tau \mathrm{m}}$ & $\mathrm{R}_{\tau \mathrm{m}}$ \\
\hline-734 & 48 & 84 & -7 & 21 & 84 \\
\hline
\end{tabular}

$\sigma_{\mathrm{m}}$ : normal stress for all batches: 20 samples $(\mathrm{MPa})$

$\mathrm{r}_{\sigma}$ : Repeatability of the normal stress of the material (MPa)

$\mathrm{R}_{\sigma}$ : Reproducibility of the normal stress of the material (MPa)

$\tau_{\mathrm{m}}$ : Shear stress for all batches: 20 samples $(\mathrm{MPa})$

$\mathrm{r}_{\tau}$ : Repeatability of the shear stress of the material (MPa)

$\mathrm{R}_{\tau}$ : Reproducibility of the shear stress of the material (MPa)

- Sample Characteristics:

\begin{tabular}{|c|c|c|c|c|c|}
\hline$\sigma_{\mathrm{e}}$ & $\mathrm{r}_{\sigma \mathrm{e}}$ & $\mathrm{R}_{\sigma \mathrm{e}}$ & $\tau_{\mathrm{e}}$ & $\mathrm{r}_{\tau \mathrm{e}}$ & $\mathrm{R}_{\tau \mathrm{e}}$ \\
\hline-741 & 39 & 67 & -11 & 16 & 28 \\
\hline
\end{tabular}

$\sigma_{\mathrm{e}}$ : normal stress for this given sample (MPa)

$\mathrm{r}_{\sigma}$ : Repeatability of the normal stress of this given sample (MPa)

$\mathrm{R}_{\sigma}$ : Reproducibility of the normal stress of this given sample (MPa)

$\tau_{\mathrm{e}}$ : Shear stress for this given sample (MPa)

$\mathrm{r}_{\tau}$ : Repeatability of the shear stress of this given sample (MPa)

$\mathrm{R}_{\tau}$ : Reproducibility of the shear stress of this given sample (MPa)

- Nota: the Repeatability and Reproducibility are respectively equal to 2,8 times the standard deviation of repeatability and 2,8 times the standard deviation of reproducibility in the case of simple comparison

- Experimental conditions

Crystallographic plane: $\{311\}$

Radiation: $\mathrm{Mn} \mathrm{K}_{\alpha}$

Spot size (on the sample surface and at $\psi=0^{\circ}$ ): $2,7 \mathrm{~mm}^{2}$

Location of measurement: Center of the spotted face

Minimum number of $\psi$ angles: 13

$\mathrm{X}$-ray elasticity constants:

$\mathrm{S}_{1\{211\}}=-1.53 * 10^{-} 6 \mathrm{MPa}^{-1}$

$1 / 2 \mathrm{~S}_{2\{211\}}=6.43 * 10^{-} 6 \mathrm{MPa}^{-1}$

The measurements are carried out in the direction of the sample length indicated with an arrow without mask on the surface and without oscillation.

- Use of sample values:

1. Choice of values for validation and qualifications: $\sigma_{\mathrm{m}}$ and $\tau_{\mathrm{m}}$ or $\sigma_{\mathrm{e}}$ and $\tau_{\mathrm{e}}$ (material/sample). This choice depends on the quality system of the laboratory. This pair of values will be called true stress $\sigma_{\text {true }}$ and $\tau_{\text {true }}$ to calculate the critical difference. 
2. Choice of the number $\mathrm{n}$ of measurements to be carried out on this sample in the repeatability conditions for the qualification or verification of the system. The number $n$ ( $n \geq 1$ for the verification or $\mathrm{n} \geq 4$ for qualification) depends on the quality system of the laboratory.

3. Calculation of the critical difference:

$$
D C_{\sigma}=\frac{1}{\sqrt{2}} \sqrt{R_{\sigma}^{2}-r_{\sigma}^{2}\left(\frac{n-1}{n}\right)} \text { and } D C_{\tau}=\frac{1}{\sqrt{2}} \sqrt{R_{\tau}^{2}-r_{\tau}^{2}\left(\frac{n-1}{n}\right)}
$$

4. Measurements on the reference sample: $n: \sigma_{i}$ et $\tau_{\mathrm{i}}(\mathrm{i}=1$ à $\mathrm{n})$ and calculation of the mean stress:

$$
\bar{\sigma}=\frac{1}{n} \sum_{i=1}^{n} \sigma_{i} \quad \text { and } \quad \bar{\tau}=\frac{1}{n} \sum_{i=1}^{n} \tau_{i}
$$

5. The goniometer is considered as qualified or validated if both conditions are respected:

$$
\left|\sigma_{\text {true }}-\bar{\sigma}\right| \leq D C_{\sigma} \quad \text { and } \quad\left|\tau_{\text {true }}-\bar{\tau}\right| \leq D C_{\tau}
$$

At Senlis, $\operatorname{xxxxxx} 2013$

On behalf of Groupement Français d'Analyse de Contraintes (GFAC),

\section{Philippe LE BEC}

EDF

In charge of material round-robin
Fabien LEFEBVRE

CETIM

In charge of the working group

\section{References}

[1] Norme XPA 09-285, Essais non destructifs : Méthodes d'essais pour l'analyse des contraintes résiduelles par diffraction des rayons X, Indice de classement A 09-285, Mai 1999.

[2] M. Francois, F. Convert, S. Branchu, French round-robin test of X-ray stress determination on a shot-peened steel, Experimental mechanics, 2000, vol. 40, no4, 361-368

[3] M. Francois, R. Botzon, Echantillons de référence pour l'analyse des contraintes par diffraction des rayons X, Action n¹ : Avril 1997 à octobre 1999, report, University of Nantes

[4] M. Francois, C. Ferreira, R. Botzon, reference specimens for X-ray stress analysis: the French experience, Metrologia 41 (2004) 33-40

[5] C. Ferreira, M. Francois, R. Guillen, Round Robin test for X-ray stress analysis standards: optimisation for discrepancy reduction, J. Strain Analysis for Engineering Design, vol. 43, (2008) $67-74$.

[6] EN_15305 - 2009 Non-destructive testing - Test method for residual stress analysis by X-ray diffraction

[7] ISO 5725-1993 1993 Accuracy (Trueness and Precision) of Measurement Methods and Results, Parts 1-6 (Geneva: International Standardization Organization) 